\title{
Prevalence of hypertension in Ethiopia: a systematic meta-analysis
}

\author{
Kelemu Tilahun Kibret ${ }^{1 *}$ and Yonatan Moges Mesfin ${ }^{2}$
}

\author{
* Correspondence: \\ ktwu21@gmail.com \\ ${ }^{1}$ Department of Public Health, \\ Wollega University, Nekemte, \\ Ethiopia \\ Full list of author information is \\ available at the end of the article
}

\begin{abstract}
Background: Hypertension has been increasing in developing countries including Ethiopia. Other than smaller studies, there is no national prevalence study on hypertension in Ethiopia. These smaller studies reported varied prevalence of hypertension. This study is intended to summarize and pool the results of smaller region based studies to provide a national level estimate of the prevalence of hypertension.

Methods: The studies were identified through internet search using the data base of MEDLINE/PubMed, Google scholar, EMBASE, HINARI, Cochrane library and reference lists of previous prevalence studies. We also made manual searches to identify relevant articles. Descriptive information for the original studies is presented in a table and the quantitative results were presented in forest plots. The Cochrane $\mathrm{Q}$ test and $\mathrm{I}^{2}$ test statistic were used to test heterogeneity across studies. The Pooled estimate of prevalence of hypertension was computed by a random effects model.

Results: One hundred eight titles were identified through electronic searching using keywords. Of these, nine studies were meet the inclusion criteria. A random effect meta-analysis of the results from these 9 studies was conducted to provide an estimate of the prevalence of hypertension in the Ethiopian population. The analysis showed that the prevalence of hypertension among Ethiopian population was estimated to be $19.6 \%$ (95 \% Cl: $13.7 \%$, $25.5 \%$ ). Subgroup analyses indicated that the prevalence of hypertension is higher in the urban population (23.7 \%) than rural and urban combined (14.7\%). The prevalence of hypertension among males (20.6\%) and females (19.2\%) was similar.

Conclusion: This study found that the prevalence of hypertension in Ethiopia is increasing. This evidence suggests that attention has to be given to primary prevention of hypertension in the Ethiopian adult population, especially in the urban population by integrating it with health extension programs.
\end{abstract}

Keywords: Hypertension, Ethiopia, Prevalence, Blood pressure, Systolic, Diastolic

\section{Background}

Hypertension is a condition in which the blood pressure in arteries or veins is abnormally high and defined as a systolic blood pressure equal to or above $140 \mathrm{~mm} \mathrm{Hg}$ and/ or diastolic blood pressure equal to or above $90 \mathrm{~mm} \mathrm{Hg}$ [1]. Non-communicable diseases (NCDs) are the major cause of death in the world, accounting for more than 36 million (63\%) of the 57 million deaths that happened in 2008. Almost half, (48 \%) of NCD deaths are due to cardiovascular diseases (CVD) [2]. Hypertension is one of the main modifiable risk factors for CVD [3].

(c) 2015 Kibret and Mesfin. Open Access This article is distributed under the terms of the Creative Commons Attribution 4.0 International License (http://creativecommons.org/licenses/by/4.0/), which permits unrestricted use, distribution, and reproduction in any medium, provided you give appropriate credit to the original author(s) and the source, provide a link to the Creative Commons license, and indicate if changes were made. The Creative Commons Public Domain Dedication waiver (http://creativecommons.org/ publicdomain/zero/1.0/) applies to the data made available in this article, unless otherwise stated. 
The prevalence of raised blood pressure in adults older than 25 years of age was about $40 \%$ in 2008 [4] and contributed to $12.8 \%$ of the total deaths in the world [5]. The World Health Organization (WHO) estimated that around $62 \%$ of CVDs and $49 \%$ of ischemic heart diseases are attributable to high blood pressure in the world [6].

Hypertension is the $4^{\text {th }}$ contributor to premature deaths in developed countries and the $7^{\text {th }}$ in developing countries [7]. Until now, communicable diseases, maternal, and nutritional causes were responsible for the highest burden of morbidity and mortality in Africa [8]. Most recently it has been shifting towards non-communicable diseases and developing countries are facing what is known as "double burden of diseases" [9]. Similarly, in the first half of the twentieth century, high blood pressure was almost non-existent in African societies, but currently estimates show that in some settings in Africa more than 40 percent of adults have hypertension $[1,10]$.

Although hypertension is a preventable and modifiable risk factor of CVD, the prevention and control of hypertension has not yet received due attention in many developing countries $[5,10]$. Ethiopia is one of the lower income countries that has affected by double burden diseases. The WHO 2011 report showed that $34 \%$ of all deaths in Ethiopia were due to NCDs, from which CVD contributes $15 \%$ [2]. A burial surveillance in Addis Ababa also revealed that $51 \%$ of all deaths were due to NCDs, of which CVD was a main cause of death (24\%), and hypertension was responsible for $12 \%$ of the CVD deaths [11]. Another cross-sectional study in South West Ethiopia reported that hypertension contributed $30.9 \%$ of cardiac cases [12]. Different studies in Ethiopia revealed that increased risk of hypertension was associated with older age (> $=45$ years), obesity [13], smoking [14] and chat chewing [14, 15].

An up-to-date and comprehensive assessment of the evidence concerning hypertension in Ethiopia is lacking. One community-based cross sectional study done in Addis Ababa showed that the age adjusted prevalence of high blood pressure was $31.5 \%$ among males and $28.9 \%$ among females [16].

Other than reginal studies done in different part of the country, there is no national prevalence study on hypertension in Ethiopia. The prevalence of hypertension also varied largely across these small studies [16-18]. The aim of this study was to estimate the prevalence of hypertension at national level by using the results from these smaller reginal studies. Given the fact that hypertension has been rising in developing countries including Ethiopia, this meta-analysis is designed to consolidate the available data to determine the current magnitude of hypertension among the Ethiopian population.

\section{Methods}

\section{Study design and search strategy/data source}

A systematic meta-analysis was done using published and unpublished articles on prevalence of hypertension in Ethiopia. The studies were found through internet searches using database of MEDLINE/PubMed, Google scholar, EMBASE, HINARI, Cochrane Library and reference lists of previous prevalence studies. The search was done using the following keywords individually or in combination: hypertension, Ethiopia, prevalence, blood pressure, systolic, diastolic. The limit for language was English and the limit for study category was human. The searching of articles was carried out from June, 2014 to November, 2014. 


\section{Study selection}

Studies were selected for the meta-analysis if they were conducted in Ethiopia and reported the prevalence of hypertension. After preliminary screening of all the titles obtained from our searches, all abstracts were then assessed for eligibility by two independent researchers based on the inclusion criteria. Disagreement between the two researchers was resolved through discussion and consensus. Finally, studies that met all of the following criteria were included in the meta-analysis: 1) cross-sectional study; 2) conducted in age group of 15 years and above and done in Ethiopia; 3) for classification of hypertension, studies that used the cut-off value of $\geq 140 \mathrm{mmHg}$ and $\geq 90 \mathrm{mmHg}$ for systolic and diastolic blood pressure respectively or studies that used self-reported use of antihypertensive medication. Studies that used blood pressure measurement on a single visit were also considered; 4) having response rate of $\geq 80 \%$ (it is the proportion of study participants who gave appropriate response to the study among the sample); 5) reported prevalence of hypertension; 6) the studies that contained original data; 7) Random sampling from a defined population or studies involving entire populations; 8) studies that reported quality assurance methods.

The reviews, letters to editors, case series and case-control studies were excluded from analysis because of insufficient data.

\section{Data extraction/abstraction}

The data extraction was done by two researchers (KT, YM) using a standardized and pretested format. Data extraction included: title, first author, publication year, year of survey, design of the study, study base (population-based or hospital-based), settings (urban, rural), sample size, data collection procedure, age group of study participants, response rate, region of study (study site in the country), sampling methods, definition(s) used for hypertension, prevalence of hypertension (age adjusted or unadjusted if stated). The overall prevalence rate as well as prevalence of hypertension by sex and residency subcategories was also extracted. Disagreements on data extractions between the two investigators were solved by discussion and consensus.

\section{Operationalization of outcome measures}

The primary outcome measure was the percentage of individuals having systolic blood pressure $\geq 140 \mathrm{mmHg}$ and/or diastolic blood pressure $\geq 90 \mathrm{mmHg}$. The prevalence of hypertension was calculated by dividing the number of individuals with systolic blood pressure $\geq 140 \mathrm{mmHg}$ and/or diastolic blood pressure $\geq 90 \mathrm{mmHg}$ by the total number of study subjects (sample), and multiplied by 100 .

\section{Quality assessment}

Reporting of response rate greater than or equal to $80 \%$, appraisal of internal validity of study results, appropriate sampling methods, clear data collection methods and procedures, reported quality assurance methods (training of data collectors, pretesting, and supervision) and representative sample size were considered as study quality indicators. All assessments were entered into preformatted and standardized data extraction forms. Studies were evaluated for quality by using these indicators; those with 
medium (fulfilling $50 \%$ of quality assessment criteria) and high quality were included for analysis. High quality studies were studies that reported all the above stated points.

\section{Synthesis of results/statistical analysis}

The data entry and analysis was done using Epi data version 3.1 and STATA version 11.0 (STATA Corporation, College Station Texas) software respectively. The original articles were described using forest plot and table. Since there was heterogeneity among studies, random effect model was used to compute the pooled prevalence of hypertension. Random effect model is more conservative than fixed effect model and takes into account any heterogeneity inherent in the meta-analysis. The estimated pooled prevalence rate with its $95 \%$ confidence interval (CI) was presented.

\section{Sub-group analyses}

Sub-group analyses were performed for residency (urban and rural/urban) and sex (male and female).

\section{Heterogeneity and publication bias}

Statistical heterogeneity was evaluated by Cochran's Q test, which shows the amount of heterogeneity between studies and $\mathrm{I}^{2}$ statistic. The $\mathrm{I}^{2}$ provides an estimate of the percentage of the variability in effect estimates that is due to heterogeneity rather than sampling error or chance differences. So, the existence of heterogeneity was verified using Cochran's $\mathrm{Q}$ test $\left(P<0.10\right.$ indicates statistically significant heterogeneity) and $\mathrm{I}^{2}$ test that measures level of statistical heterogeneity between studies (values of $25 \%, 50 \%$ and $75 \%$ are to mean low, medium and high heterogeneity respectively).

The Egger weighted regression and Begg rank correlation test methods were used to statistically assess publication bias $(P<0.05$ was consider as suggestive of statistically significant publication bias).

\section{Results}

Identified studies

We identified 108 titles by the electronic search in MEDLINE/PubMed, Google scholar, EMBASE, HINARI, Cochrane Library and reference lists of previous prevalence studies. Of which 99 were excluded (51 due to duplication, 30 through review of titles, 10 by reviewing of abstracts, and 8 full text articles due to inclusion criteria). Finally, nine studies were found to be eligible and included in the meta-analysis (Fig. 1).

\section{Study characteristics}

A total of nine studies were included in the meta-analysis. Seven of them were population based [3, 16-21] and two were hospital/institution based [22, 23]. All are cross sectional studies which had study population varied from 395 in Sidama [23] to 3223 in South West Ethiopia of Gilgel Gibe [17], and were conducted between the year 2009 and 2014. These studies represented five regions of country: (Amhara [3], Oromia [18, 22], Southern Region [17, 21, 23], Tigray [20] and Addis Ababa [16, 19] (Table 1). Eight studies described the prevalence of hypertension in both sexes as presented in Table 2. 


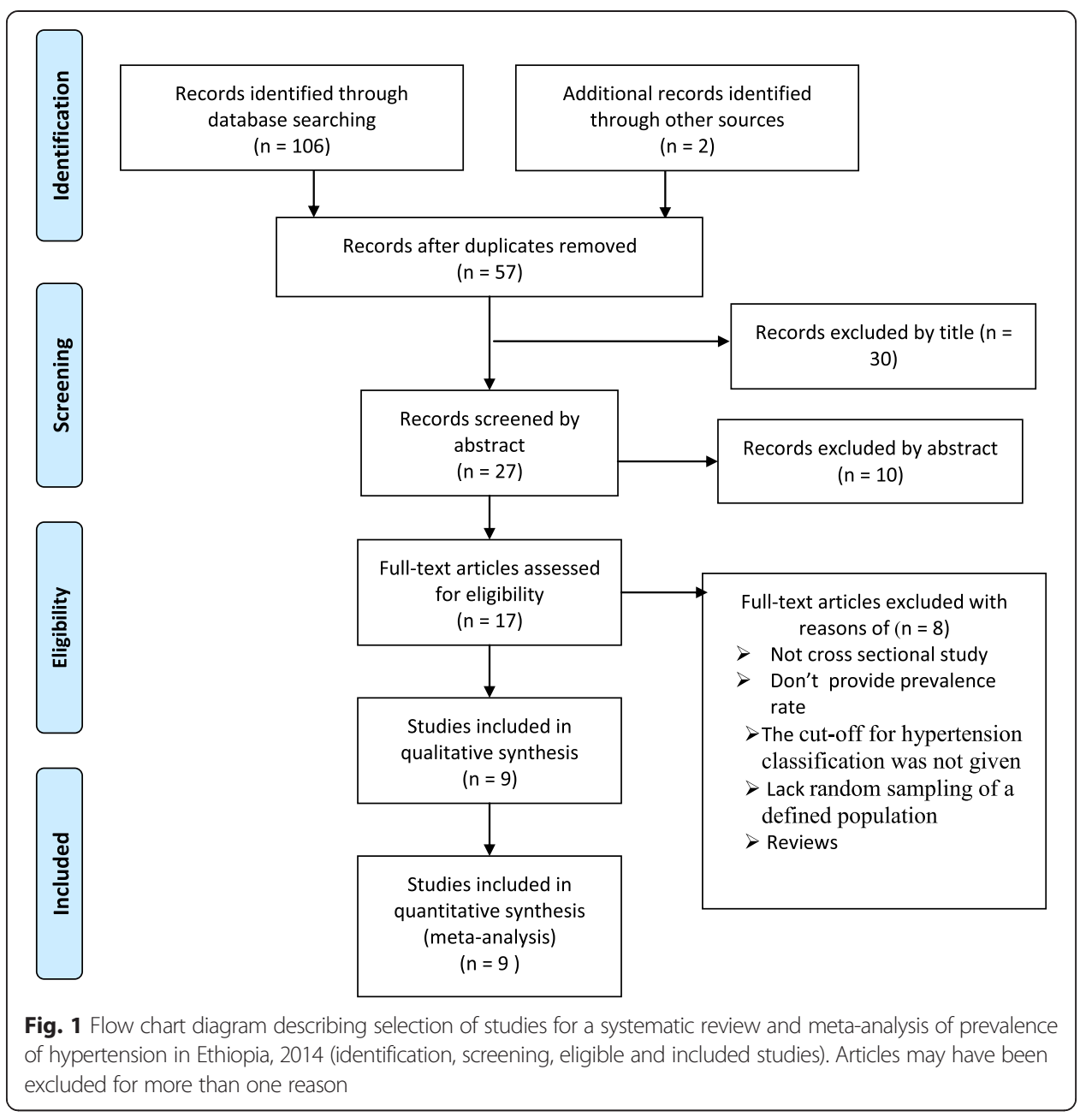

\section{Heterogeneity and publication bias}

The included articles exhibited high heterogeneity according to Cochrane $\mathrm{Q}$ test ( $\mathrm{Q}$ test $p=0.001)$ and $\mathrm{I}^{2}$ test $\left(\mathrm{I}^{2}=98.6 \%\right)$, which is indicative to using random effects model. But the Egger weighted regression statistics $(p=0.12)$ and Begg rank correlation statistics $(p=0.6)$ indicated no evidence of publication bias.

\section{Meta-analysis}

The analysis of nine studies, according to the Der Simonian-Laird random-effects model, revealed that the pooled prevalence of hypertension among the Ethiopian population was 19.6 \% (95 \% CI: 13.7 \%, $25.5 \%$ ) (Fig. 2). Subgroup analyses showed that the prevalence of hypertension in the urban population was $23.5 \%$ (95 \% CI 17.7, 29.2) and that of both rural \& urban population was $14.7 \%$ (95 \% CI: 9.7, 19.7) (Fig. 2). This meta-analysis also revealed that prevalence of hypertension among males and females was $20.6 \%$ (95 \% CI: $14.6 \%, 26.7)$ and 19.2 (95\% CI: $13.3 \%$, 25.0) respectively, which was estimated by using eight studies (Figs. 3 \& 4). 
Table 1 Descriptive summary of the nine studies on prevalence of hypertension in Ethiopia and included in the meta-analysis, 2014

\begin{tabular}{|c|c|c|c|c|c|c|c|}
\hline $\begin{array}{l}\text { Author } \\
\text { (Publication year) }\end{array}$ & Region & $\begin{array}{l}\text { Settings } \\
\text { (urban/rural) }\end{array}$ & $\begin{array}{l}\text { Study base } \\
\text { (population based/hospital-based) }\end{array}$ & $\begin{array}{l}\text { Age group } \\
\text { of subjects }\end{array}$ & Sample size & Response rates (\%) & $\begin{array}{l}\text { Prevalence with } \\
\text { its } 95 \% \mathrm{Cl}\end{array}$ \\
\hline Awoke A et al. [3] 2012 & Gondar/Amhara & Urban & Population & $>=35$ & 679 & 97.6 & $28.3(24.9-31.7)$ \\
\hline Tesfaye F et al. [16] 2009 & Addis Ababa & Urban & Population & $25-64$ & 3273 & 88.1 & $30.3(28.7-31.9)$ \\
\hline Bonsa F et al. [18] 2014 & Bedele/Oromia & Urban & Population & $>=15$ & 396 & 93.8 & $16.9(13.2-20.6)$ \\
\hline Gudina EK et al. [22] 2013 & Jimma/oromia & $\begin{array}{l}\text { Urban/rural } 57 \% \\
\text { from rural }\end{array}$ & Hospital based & $>=15$ & 774 & 94.83 & $13.2(10.8-15.6)$ \\
\hline Nshisso LD et al. [19] 2012 & Addis Abba & Urban & Gov't employee & $>15$ & 2153 & 100 & $19.1(17.1-20.8)$ \\
\hline Giday A et al. [23] 2010 & Sidama zone/Southern Region & Both Urban \& rural & Hospital/Population & $15-80$ & $444 / 395$ & 88.9 & $18.8(15.1-23.1)$ \\
\hline Mengistu MD et al. [20] 2014 & Humera/Mekele & Both Urban \& rural & Community & $>=18$ & 1183 & 100 & $18.1(15.9-20.3)$ \\
\hline Muluneh AT et al. [17] 2012 & $\begin{array}{l}\text { SW Ethiopia, Gilgel } \\
\text { Gibe/Southern Region }\end{array}$ & Both Urban \& rural & Community/population & $15-64$ & 3223 & 81.3 & $9.3(8.3,10.3)$ \\
\hline Helelo TP et al. [21] 2013 & Durame/Southern region & Urban & Population & $>=31$ & 518 & 98.6 & $22.4(18.8,26)$ \\
\hline
\end{tabular}


Table 2 Descriptive summary of the eight studies on prevalence of hypertension in Ethiopia according to sex of the subjects included in the meta-analysis, 2014

\begin{tabular}{|c|c|c|c|c|c|c|c|c|}
\hline \multirow{2}{*}{$\begin{array}{l}\text { Author } \\
\text { (year of Publication) }\end{array}$} & \multirow[t]{2}{*}{ Region in the Country } & \multirow[t]{2}{*}{ Settings (urban/rural) } & \multirow{2}{*}{$\begin{array}{l}\text { Age of } \\
\text { subjects }\end{array}$} & \multirow[t]{2}{*}{ Sample size } & \multirow{2}{*}{$\begin{array}{l}\text { No. of } \\
\text { males }\end{array}$} & \multirow{2}{*}{$\begin{array}{l}\text { No. of } \\
\text { females }\end{array}$} & \multicolumn{2}{|c|}{ Prevalence of hypertension with its $\mathrm{Cl}$ among } \\
\hline & & & & & & & Males & Females \\
\hline Awoke A et al. [3] 2012 & Gondar/Amhara & Urban & $>=35$ & 679 & 323 & 356 & $26(21.4-31)$ & $30.3(25.6-35.3$ \\
\hline Tesfaye F et al. [16] 2009 & Addis Ababa & Urban & $25-64$ & 3273 & 1538 & 2175 & $31.5(29-33.9)$ & $28.9(26.8-30.9)$ \\
\hline Bonsa F et al. [18] 2014 & Bedele/Oromia & Urban & $>=15$ & 396 & 267 & 129 & $13.1(9.6-17.7)$ & $24.8(18.2-32.9)$ \\
\hline Gudina EK et al. [22] 2013 & Jimma/oromia & Urban/rural $57 \%$ from rural & $>=15$ & 774 & 308 & 426 & $15.3(11.7-19.7)$ & $11.7(9.0-15.1)$ \\
\hline Nshisso LD et al. [19] 2012 & Addis Abba & Urban & $>15$ & 2,153 & 1298 & 855 & $22(20.2-23.8)$ & $14.9(13.4-16.4)$ \\
\hline Giday A et al. [23] 2010 & Sidama zone/Southern Region & Both Urban \& rural & $15-80$ & 395 & - & - & -- & - \\
\hline Mengistu MD et al. [20] 2014 & Humera/Mekele & Both Urban \& rural & $>=18$ & 1183 & 443 & 740 & $21(17.5-25.0)$ & $16.4(13.9-19.2)$ \\
\hline Muluneh AT et al. [17] 2012 & SW Ethiopia,Gilgel gibe/Southern Region & Both Urban \& rural & $15-64$ & 3223 & 1541 & 1682 & $10.3(8.8-11.9)$ & $8.5(7.3-9.9)$ \\
\hline Helelo TP et al. [21] 2013 & Durame/Southern Region & Urban & $>=31$ & 518 & 229 & 289 & $26.2(20.9-32.3)$ & $19.4(15-24)$ \\
\hline
\end{tabular}




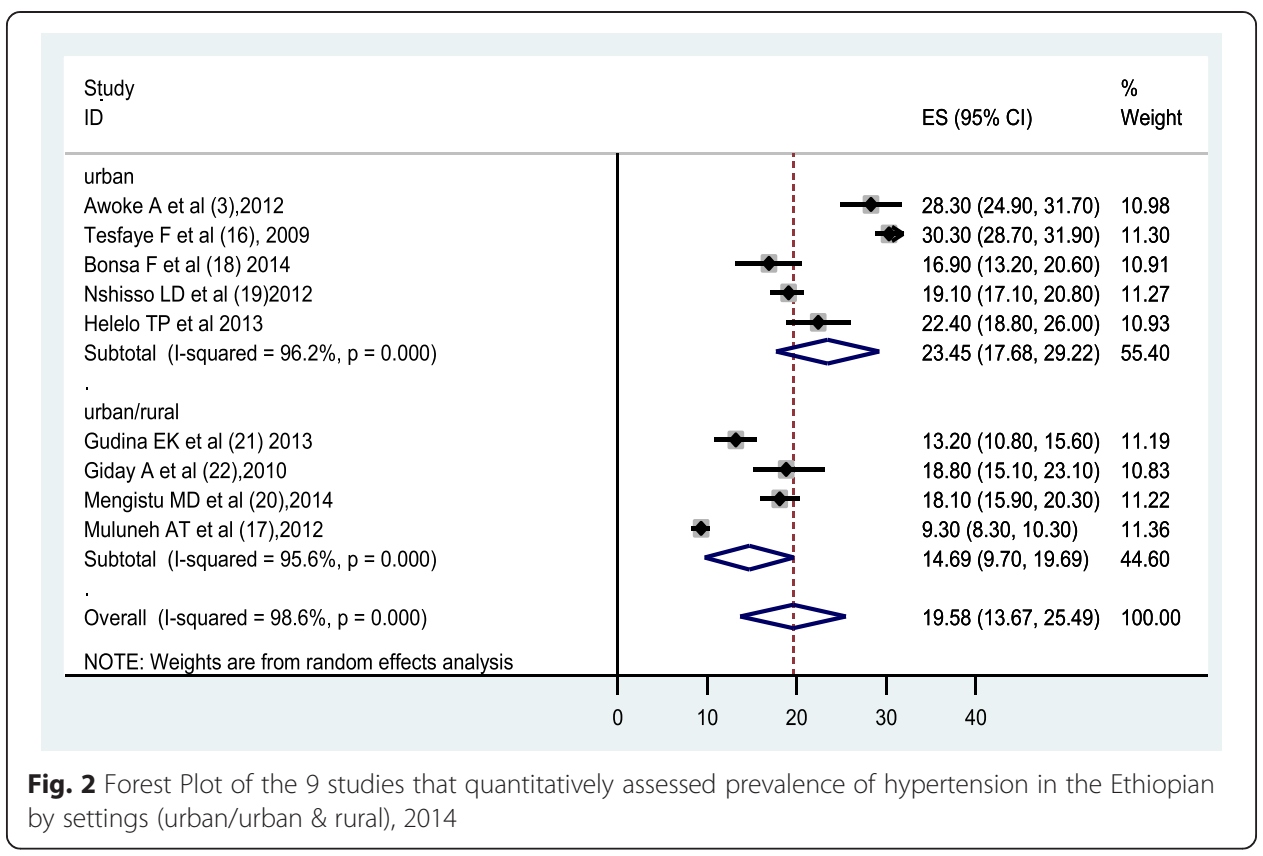

\section{Discussion}

This meta-analysis determined the pooled prevalence of hypertension in Ethiopia using nine studies. According to the results of this meta-analysis, the prevalence of hypertension in Ethiopia was estimated to be 19.6 \% (23.5 \% in urban population and $14.7 \%$ in rural/urban population). This study also shown that the prevalence of hypertension in males and females was $20.6 \%$ and $19.2 \%$ respectively.

The highest prevalence of hypertension (30.2 \%) was reported in a study done in Addis Ababa urban population [16]. But , Muluneh et al. detected a lower prevalence of hypertension $(9.3 \%)$ in urban/rural population of South West Ethiopia (Gilgel Gibe) [17]. The

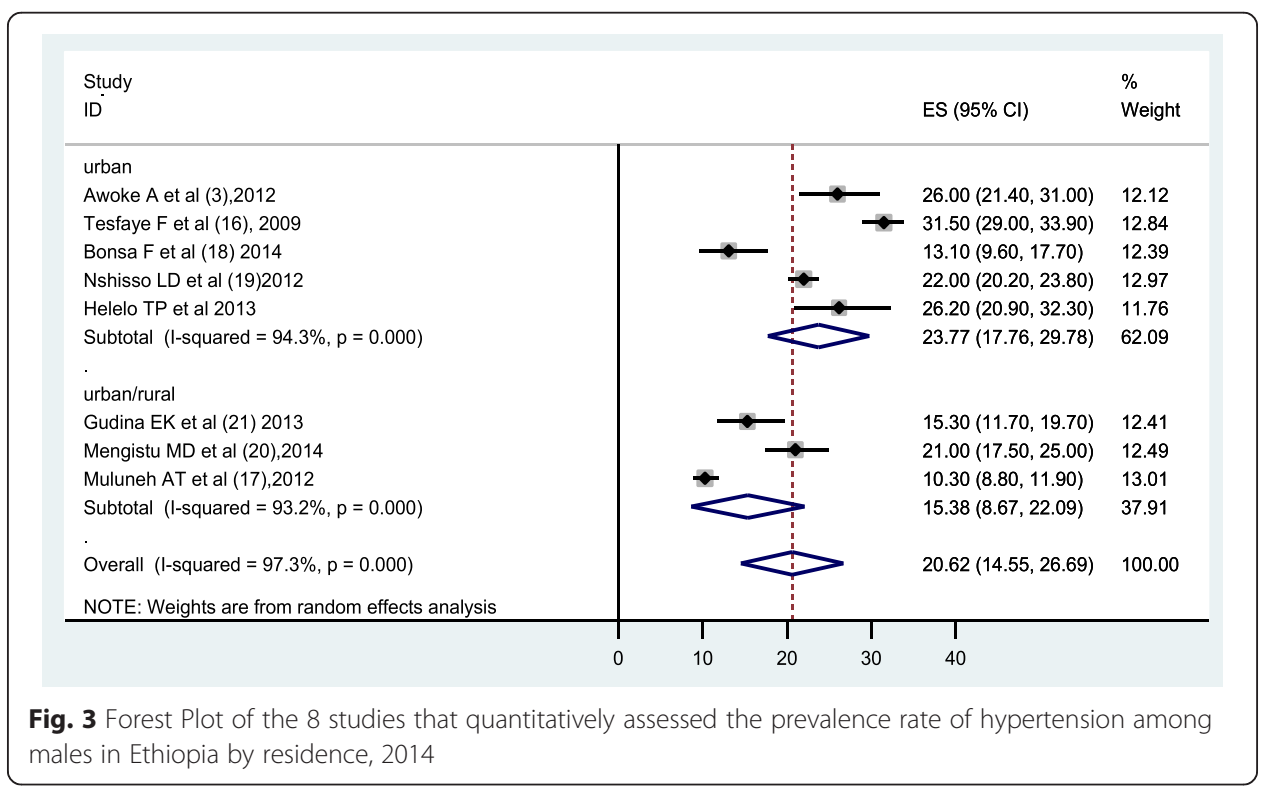




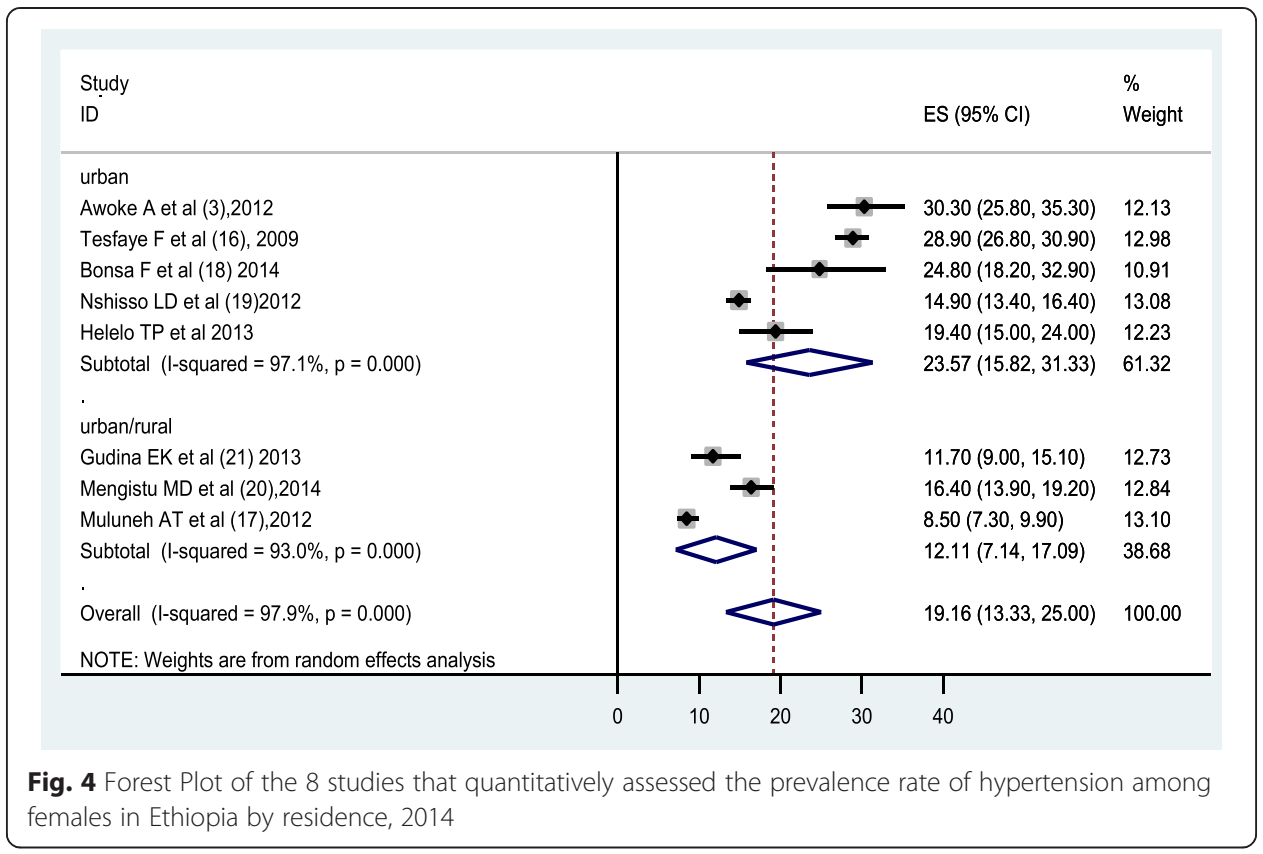

overall pooled prevalence in our study is comparable to a nationwide study in Gambian population [24]. But, it is lower than a community-based study conducted in one Uganda district [25]. This dissimilarity might be due to difference in study subjects. For example our analysis considers adults older than 15 years of age but the Ugandan study included study subjects who are 20 years and older. There might be also socio-economic and cultural differences.

The prevalence of hypertension was found to be higher in the urban population than the mixed urban/rural population one. This is consistence with the results of a systemic review in Africa and sub-Saharan Africa [26, 27]. The higher prevalence of hypertension in urban areas might be due to living lifestyle differences. Higher levels of obesity, increased salt and fat intake from consuming more processed foods and engaging in jobs with minimal physical activity are possible explanations for higher hypertension in urban populations

Awoke et al. (28.3 \%) [3], Tesfaye et al. (30.27 \%) [16], Bonsa et al. (16.9 \%) [18] and Nshisso et al. (19.1\%) [19] reported that the prevalence of hypertension in urban population ranged $16.9 \%-30.27 \%$ in between 2009 and 2014. This meta-analysis summarized all these findings and shows the prevalence of hypertension was $23.5 \%$ in the urban population of Ethiopia.

In the combined rural/urban population, the highest prevalence of hypertension (18.8 \%) was reported in Sidama [23] and the lowest prevalence (9.3 \%)) was observed in the South West Ethiopia (Gilgel Gibe) [17]. This meta-analysis shown a pooled prevalence rate of $14.7 \%$ among the rural/urban population of Ethiopia. This is higher than the result of study done in Rural Nigeria. The difference might be due to sociocultural factors and study periods difference, as the Nigeria study was conducted in 1991-1995 [26].

The lower prevalence among males (10.3\%) and females (8.5\%) was reported by Muluneh et al. [17] while the higher prevalence, $31.5 \%$ among males and $30.3 \%$ 
among females was documented by Tesfaye et al. [16] and Awoke et al. [3] respectively. This meta-analysis found the overall pooled prevalence of hypertension was $20.6 \%$ among males and $19.2 \%$ among females. This is inconsistence with study done in Gambia [24], which reported higher prevalence among females. This difference might be due to socio cultural difference and different criteria used to diagnose hypertension, the Gambia study used SBP/DBP > =160/95.

Even though hypertension is easily diagnosable and treatable with lifestyle modifications and effective medicines and it was $7^{\text {th }}$ contributor to premature death in developing countries [7] and responsible for $12 \%$ of the CVD deaths in Addis Abba, Ethiopia [11]. Furthermore, hypertension control provides an entry point to deal with other NCDs as any intervention will help to concomitantly address other NCDs as well $[6,9]$. Health education programs that promote exercise, weight reduction, early diagnosis and screening are some of the key interventions that will be promoted at various levels of health facilities. Ethiopia has been effectively implementing the health extension program by deploying health extension workers at grass root level in the community for the maternal and communicable diseases. This program should also incorporates hypertension as one component and health extension workers can carried out screening and teach the community about prevention mechanisms.

\section{Strengths and limitations}

The strength of this study includes use of multiple databases to search articles (both manual and electronic search) for meta-analysis, abstraction of information uniformly using a predetermined and pretested standard format by two independent reviewers that helped to minimize error. This meta-analysis also included studies from different parts of the country that comprises both urban and rural population.

There are some potential limitations to this study. This analysis was based on limited studies (only nine cross sectional studies) which have had varied study subjects in terms of age, socio-cultural and bio-behavioral characteristics that might have effect on prevalence of hypertension. Even though it incorporates articles from different regions of the country, still the representativeness of the population is not as strong. We used the same criteria for the diagnosis of hypertension (systolic blood pressure $\geq 140 \mathrm{mmHg}$ and/or diastolic blood pressure $\geq 90 \mathrm{mmHg}$ or self-reported use of antihypertensive medication) for all articles included in the analysis. But still diagnosis of hypertension might be varied between studies and could have an impact on the result.

The analysis was based on studies having different characteristics. To address the issue of potential variability across studies, the analysis was performed by using random effect model. Under the random effects model the true effects in the studies are assumed to vary between studies and the summary effect is the weighted average of the effects reported in the different studies. The random effect model takes into considerations of any heterogeneity inherent in the meta-analysis and tend to give more conservative estimate.

\section{Conclusion}

The pooled estimate does provide an overview of the magnitude of the problem of hypertension in the Ethiopian population. This evidence suggests Ethiopia is 
affected by double burden diseases so that policies and interventions should give attention and prioritization for reduction of hypertension in the Ethiopian adult population. A rising prevalence of hypertension in the population must trigger the policy makers and health care professionals as this is an area where primary prevention measures can bring about a substantial reduction in cardiovascular morbidity and mortality in the future. Further national population based studies are required for more accurate estimate of the prevalence of hypertension in the urban and rural population of the Ethiopia.

\author{
Abbreviations \\ CVD: Cardiovascular Diseases; DALYS: Disability Adjusted Life Years; DBP: Diastolic Blood Pressure; NCDs: Non \\ Communicable diseases; SBP: Systolic Blood Pressure; WHO: World Health Organization.
}

\title{
Competing interests
}

The authors declare that they have no competing interests.

\section{Authors' contributions}

KTK was the principal investigator who contributed to the conception and design of the study, collected, entered, analyzed, interpreted the data, prepared the manuscript and acted as corresponding author. YMM contributed to data analysis, interpretation and drafted the manuscript. All authors read and approved the final manuscript.

\section{Author details}

${ }^{1}$ Department of Public Health, Wollega University, Nekemte, Ethiopia. ${ }^{2}$ Department of Public Health, Haramaya University, Harar, Ethiopia.

Received: 15 June 2015 Accepted: 25 November 2015

Published online: 09 December 2015

\section{References}

1. World Health Organization. A global brief on hyper tension World Health Day. 2013.

2. World Health Organization. Non communicable diseases country profiles. 2011.

3. Awoke A, Awoke T, Alemu S, Megabiaw B. Prevalence and associated factors of hypertension among adults in Gondar, North west Ethiopia:a community based cross-sectional study. BMC Cardiovasc Disord. 2012;12:113.

4. World Health Organization. Global Health Repository. Raised blood pressure: situation and trends. 2013. http://www. who.int/gho/ncd/risk_factors/blood_pressure prevalence text/en/.

5. World Health Organization. Global status report on non communicable diseases 2010. 2011.

6. World Health Report-2013. Reducing Risks, Promoting Healthy Life. http://www.who.int/whr.

7. Dreisbach AW. Epidemiology of Hypertension. Supplement to JAPI February 2013; 61:12-13.

8. Lopez DA, Mathers C, Ezzati M. Global burden of disease and risk factors. Washington, DC: Oxford University Press and World Bank; 2006. Available at: http://www.ncbi.nlm.nih.gov/books/NBK11812/GoogleScholar.

9. Bygbjerg IC. Double burden of noncommunicable and infectious diseases in developing countries. Science. 2012; 337(6101):1499-501. PubMed | Google Scholar.

10. Vijver SVD, Akinyi H, Oti S, Olajide A, Agyemang C, Aboderin I, et al. Status report on hypertension in Africa Consultative review for the $6^{\text {th }}$ Session of African Union Conferee of Ministers of Health on NCDs. Pan Afr Med J. 2013;16:38. doi:10.11604/pamj.2013.16.38.3100. http://www.ncbi.nlm.nih.gov/pmc/articles/PMC3932118/.

11. Misganaw A, Mailemrariam D, Araya T. The double mortality burden among adults in Addis Ababa, Ethiopia, 2006-2009. Prev Chronic Dis. 2012;9:110142. doi:http://dx.doi.org/10.5888/pcd9.110142. Available at: http://www. ncbi.nlm.nih.gov/pmc/articles/PMC3396553/.

12. Habte B, Alemseged F, Tesfaye D. The pattern of cardiac diseases at the cardiac clinic of Jimma University Specialised Hospital, South West Ethiopia. Ethiop J Health Sci. 2010 20(2): 99-105. Available at:http://www.ncbi.nlm.nih.gov/ pubmed/22434967.

13. Tamiru S, Alemseged F. Risk factors for cardiovascular diseases among diabetic patients in southwest ethiopia. Ethiop J Health Sci. 2010;20(2):121-8. Available at: http://www.ncbi.n/m.nih.gov/pmc/articles/PMC3275835/.

14. Tesfaye F, Byass P, Berhane Y, Bonita R, Wall S. Association of smoking and khat (Catha edulis Forsk) use with high blood pressure among adults in Addis Ababa, Ethiopia, 2006. Prev Chronic Dis. 2008;5(3):89.Available at: http:// www.ncbi.nlm.nih.gov/pmc/articles/PMC2483558/.

15. Getahun W, Gedif T, Tesfaye F. Khat (Catha edulis) chewing is associated with elevated diastolic blood pressure among adults in Butajira, Ethiopia: A comparative study. BMC Public Health. 2010;10(390). Available at: http:// www.biomedcentral.com/1471-2458/10/390

16. Tesfaye F, Byass P, Wall S. Population based prevalence of high blood pressure among adults in Addis Ababa: uncovering a silent epidemic. BMC Cardiovasc Disord. 2009;9 (39doi:10.1186/1471-2261-9-39). Available at: http:// www.biomedcentral.com/1471-2261/9/39.

17. Muluneh AT, Haileamlak A, Tessema F, Alemseged F, Woldemichael K. Population based survey of chronic noncommunicable diseases at Gilgel Gibe Field Research Center, Southwest Ethiopia. Ethiop J Health Sci. 2012;22(S):7-18. Available at: http://www.ncbi.nlm.nih.gov/pmc/articles/PMC3542738/.

18. Bonsa F, Gudina EK, Hajito KW. Prevalence of hypertension and associated factors in Bedele Town, Southwest Ethiopia. Ethiop J Health Sci. 2014 (24)1-26 available at http://www.ncbi.nlm.nih.gov/pmc/articles/PMC3929924/. 
19. Nshisso LD, Reese A, Gelaye B, Lemma S, Berhane $Y$, Williamsa MA. Prevalence of hypertension and diabetes among Ethiopian adults. Diabetes Metab Syndr. 2012; 6(1): 36-41. doi:10.1016/j.dsx.2012.05.005. Availanle at: http://www.ncbi nlm.nih.gov/pmc/articles/PMC3460264/.

20. Mengistu MD. Pattern of blood pressure distribution and prevalence of hypertension and prehypertension among adults in Northern Ethiopia: disclosing the hidden burden. BMC Cardiovasc Disord. 2014;14:33. Available at: http:// www.biomedcentral.com/1471-2261/14/33.

21. Helelo TP, Gelaw YA, Adane AA. Prevalence and associated factors of hypertension among adults in Durame Town, Southern Ethiopia. PLoS One.2014, 9(11): e112790. doi:10.1371/journal.pone.0112790. Available at:http://www.ncbi.nIm. nih.gov/pmc/articles/PMC4240541/.

22. Gudina EK, Michael Y, Assegid S. Prevalence of hypertension and its risk factors in southwest ethiopia: a hospitalbased cross-sectional survey. J Integ Blood Press Control. 2013;6:111-7. Available at: http://www.ncbi.nlm.nih.gov/ pmc/articles/PMC3753877/.

23. Giday A, Wolde M, Yihdego D. Hypertension, obesity and central obesity in diabetics and non diabetics in Southern Ethiopia. [Ethiop. J. Health Dev. 2010;24(2):145-147]. Available at: http://www.ajol.info/index.php/ejhd/article/view/62964.

24. Van der Sande MA, Bailey R, Faal H, Banya WA, Dolin P, Nyan OA, et al. Nationwide prevalence study of Hypertension and related non-communicable diseases in The Gambia. Trop Med Int Health. 1997;2(11):1039-48.

25. Wamala JF, Karyabakabo Z, Ndungutse D, Guwatudde D. Prevalence factors associated with hypertension in Rukungiri district, Uganda - A community-based study. Afr Health Sci. 2009;9(3):153-60. Available at: http://www. ncbi.nlm.nih.gov/pmc/articles/PMC2887031/.

26. Addo J, Smeeth L, Leon DA. Hypertension in sub-saharan Africa: a systematic review. Hypertension. 2007;50(6): 1012-8. Available at: http://hyper.ahajournals.org/content/50/6/1012.long.

27. Mufunda J, Chatora R, Ndambakuwa Y, Nyarango P, Kosia A, Chifamba J, et al. Emerging non-communicable disease epidemic in Africa: preventive measures from the WHO Regional office for Africa. Ethn Dis. 2006;16:521-6.

\section{Submit your next manuscript to BioMed Central and we will help you at every step:}

- We accept pre-submission inquiries

- Our selector tool helps you to find the most relevant journal

- We provide round the clock customer support

- Convenient online submission

- Thorough peer review

- Inclusion in PubMed and all major indexing services

- Maximum visibility for your research

Submit your manuscript at www.biomedcentral.com/submit 